\title{
Autonomía burocrática y responsabilidad *
}

\section{Brian W. Hogwood **}

\section{¿Aparente contradicción o interdependencia lógica?}

Este documento comienza con la aparente contradicción de que una agencia pública puede ser, a la vez, independiente y responsable de rendir cuentas, como muestra la propuesta laborista de crear una Agencia de Criterios Alimenticios Independiente. Sin embargo, si una agencia no tiene autonomía de ninguna clase ¿cómo puede justificar sus acciones cuando no ha tenido función en la determinación de esas acciones? Sin duda, necesitamos vaciar los conceptos gemelos de autonomía y responsabilidad, antes de poder fijar el alcance de cada uno, lógicamente interdependiente o simplemente consistente en tensión.

Después de examinadas las posibles dimensiones de estos conceptos, realizaremos la tentativa de examinar su significado en la evolución de las agencias llamadas Next Steps dentro del gobierno inglés desde 1998 (se conocen con este nombre por el informe de la gerencia del gobierno: las Next Steps, que propuso su establecimiento y el compararlas con agencias con un concepto más genérico o corporaciones tales como la Agencia de Medio Ambiente, que tiene el término agencia en su título, pero no son el mismo tipo de organización). Examinando el significado de las agencias, la comparación será hecha con otras organizaciones departamentales y no departamentales.

\section{¿Qué clases de autonomía?}

El concepto de autonomía organizacional puede operar dentro de un extenso grupo de niveles y puede tener que ver con una variedad de aspectos del trabajo de las organizaciones. En el nivel más detallado puede que haya organizaciones sociales individualizadas autónomas, donde la decisión acerca del trato de un cliente individual o de otro tipo es responsabilidad de la organización, ya que las personas no tienen poder a quien la corporación pueda reclamar. Este tipo de autonomía tradicionalmente se ha dado en los departamentos que recaudan impuestos (Hacienda, Aduanas y Arbitrios), precisamente para excluir el compromiso de los ministerios en los asuntos de los contribuyentes individuales. Incluso el Defensor del Pueblo tiene el derecho para investigar casos individuales.

Con respecto a las decisiones sustantivas en casos individuales, son autónomas al establecer prioridades según los casos: por ejemplo, las categorías de padres ausentes podrán ser elegidas para pagos a cargo de la Agencia de Apoyo a la Infancia.

Como muestra el ejemplo, este establecimiento de prioridades tiene potenciales repercusiones políticas y de lineas de actuación, incluso si es inicialmente considerada como un asunto de prioridades operacionales dentro de una línea de actuación concreta.

Una clave de la autonomía general es la autonomía personal, hasta qué punto los altos cargos pueden determinar las cifras, grados, posición, responsabilidades y horas de trabajo del personal. Una cuestión analítica para valorar la extensión en que las agencias, como tales, están asociadas con mayor autonomía de personal; es el moviniento general hacia una mayor flexibilidad a través del Servicio Civil Británico como un todo, no sólo en las agencias que componen la mayoría (en particular a partir de la publicación en 1995 del Libro Blanco, El Servicio Civil: Continuidad de Ingresos Progresivos y Cambio). 
Los tipos de autonomía arriba señalados están considerados convencionalmente para aquellos asuntos de materias operacionales, a pesar de que nosotros habíamos observado que estableciendo prioridad para tipos de casos y para las finanzas pueden colocarse en el límite entre materias políticas y operacionales. Un rol político más explícito es la autonomía entregada al consejo político. Como verenos posteriormente, el modelo Next Steps está basado en la idea de que la ejecución partirá completamente de las agencias y la responsabilidad queda en el núcleo de los departamentos. Sin embargo, nosotros queremos saber si en la práctica las agencias pueden ofrecer consejo político o, en efecto, si los departamentos dependen de una agencia para los consejos políticos. Un tema relacionado es si el consejo político puede ser dado públicamente. El Libro Blanco del Gobierno Laborista ha propuesto las Agencias Food Stands (de manera confusa, no una Agencia Next Steps), tomando el criterio de que la "independencia" de la corporación aumentara por sus derechos para publicar el consejo político a los ministerios.

La máxima autonomía es la habilidad de hacer o definir políticas. Bajo el modelo británico se supone que es la única preservada para los ministerios y el Parlamento. En la práctica, algunos departamentos no ministeriales y en particular los reguladores de industrias individuales, tienen el poder de anunciar políticas en asuntos tales como el régimen de fijación de precios. Sus propuestas son aplicadas si no son cuestionadas por la industria, o no están sujetas a revisión por otras organizaciones no ministeriales en el caso de dudas. Ministerios y Parlamento conservan el poder para modificar o eliminar los poderes de los reguladores para hacer tales resoluciones.

\section{¿Qué clase de responsabilidad?}

El otro gemelo de nuestro par de conceptos tiene, además diferentes usos y a menudo supuestos implícitos. Nosotros utilizamos como punto de partida para el concepto de responsabilidad el enfoque de Day y KLein (1987:2).

Nuestro punto de vista es que responsabilidad es, sobre todo, la construcción de un lenguaje convenido o el uso de un discurso acerca de la dirección y la ejecución, y el criterio que debe ser usado en valorarlo. Es sobre percepciones y poder. Puede por lo tanto esperarse que varie en contextos diferentes dependiendo de la naturaleza de la situación política y el poder de los diferentes actores de la organización.

Esto refleja el énfasis en nuestro diseño de investigación sobre variaciones de responsabilidad en la práctica y los factores asociados con estas variaciones. Incluso llega al punto de que la responsabilidad es una lucha potencial en vez de simplemente un concepto legal o contractual. De este modo, nosotros además seguimos a DaY y KLEIN (1987:j) en observar que es posible no estar de acuerdo sobre el contexto - porque un actor debe aclaración a otro- o sobre el lenguaje de justificación. El actual debate sobre responsabilidad ministerial en Inglaterra, particularmente pero no exclusivamente, concierne a las agencias, demostrando que responsabilidad es un juego de conceptos.

\section{¿Qué es responsabilidad?}

Las palabras accountability y responsibility se usan frecuentemente intercambiándolas, y cuando hay intentos para diferenciarlas, al hacer la pareja y contrastarla puede tener significados opuestos dados por diferentes autores. Las definiciones del diccionario, a menudo, definen uno según términos del otro. Chambers tiene como uno de sus significados de account: •responder como único responsable: tener la responsabilidad o crédito; responsible tiene como una de sus definiciones: "poder ser llamado a responder por estar al mando y el control. La distinción o falta de ella no es simplemente una cuestión de semántica, ya que se trata de decidir si ellos, en el centro del debate en Inglaterra, encuentran diferencias en las relaciones entre ministerios, empleados civiles y el Parlamento. Este debate no es simplemente académico, ya que es discutido con pasión en debates políticos. Es en particular relevante para las Agencias Next Steps como prueba de la diferencia de opinión en esta cuestión entre el Tesoro y el Comité del Servicio Civil (1994) y Sir Robin Butler y más dramáticamente el Informe Learmont (1995) y la posterior dimisión del jefe de la Agencia del Servicio de Prisiones. Sin embargo, como el Informe Scott ha demostrado, tiene una extensa aplicación también.

En esta parte nosotros intentamos explicar los diferentes significados que puede abarcar el término accountability y su término gemelo responsibility. Un grado de esos significados diferentes puede aplicarse a un individuo particular o a una institución simultáneamente, o pueden ser ampliamente repartidos a lo largo de los diferentes titulares. Otros escritores, como DowDing (1995), han ofrecido estas clasificaciones, aunque su caso se centra en la responsabilidad de los ministros. Sobre éstos nuestra posición es la siguiente: sostenemos que estas distinciones pueden ser relevantes para los diversos aspectos de la responsabilidad relativa a la organización, ambos dentro y fuera de la organización.

Responsabilidad indudablemente tiene implicaciones normativas en el debate actual. Un examen de la derivación del termino responsabilidad indica que éste no aporta necesariamente connotaciones de democracia y participación, significados ambos que sí se aprecian en algunos usos corrientes de la palabra. 
Históricamente, responsabilidad podía ser para el rey o el tirano, o incluso para Dios a través del monarca. La responsabilidad necesita ser disiinguida conceprualmenie de la democracia o la participación, a pesar de que manifestaciones particulares de responsabilidad pueden invocarse o ser invocadas por tales conceptos. DaY y KuEIN llegaron, interesantemente, a la conclusión de que la elección no era necesaria ni una condición suficiente para el control o la responsabilidad.

Si las percepciones de los responsables son en su mayor parte determinadas por sentimientos interiorizados de una obligación y capacidad para exponer y justificar, como aconsejado por nuestra evidencia, la elección no es una condición necesaria para causarlo.

Además, en la cuestión de si tú puedes tener demasiado talento o demasiada vocación, pueden ambos confundir el asunto de quién es responsable (ver HOG WOOD, JUDGE y MCVICAR, 1998). Como mostramos posteriormente, en el caso de la Agencia del Servicio de Prisiones, llamar a la responsabilidad puede impedir enérgicamente la capacidad del directivo de una organización para administrar eficazmente la distribución de los servicios, con relación a cuál de ellos debe ser llamado para declarar.

Responsabilidad como el acuerdo y la verificación de un registro correcto

La preocupación es por la veracidad, amplitud y oportunidad de mantener y guardar los documentos, sumarios... DAY y KıEIN (1987:8) sostienen que uel concepto de responsabilidad como verificación no está ni históricamente ni lógicamente vinculado a ideas sobre responsabilidad política entendido como respuesta por la gente. DAY y KLEIN están interesados en mantener registros financieros, pero el asunto puede ser ampliado a mantener registros exactos de otro tipo, relevantes para la elaboración y distribución de la política pública. El papel de la Oficina Financiera en el Servicio Civil Británico tiene este propósito en sus comienzos, aunque no necesariamente en su conclusión. Podemos querer hacer una subdivisión nueva entre el proceso de preparación de los informes exactos y la verificación de estos informes.

Responsabilidad como el requerimiento (u obligación asumida) de proporcionar información

En contraste con el acuerdo y la verificación de los registros, este sentido de responsabilidad está relacionado con proporcionar esa información a un grupo de personas reconocidas o que exigen tener un derecho a tal información. Podría ser suministrada o de una forma rutinaria, como los documentos o informes anuales, o por solicitudes específicas cuando la información es solicitada (como una cuestión parlamentaria, una investigación del Defensor del Pueblo, o un Comité de Investigación) u ofrecida espontáneamente (como un comunicado de prensa). En el más amplio sentido esto implica presentar un informe de cuentas con un significado más amplio que simplemente numérico, de cálculo financiero o de cálculo. Este significado implica que se espera que respondan en un sentido estrició al ofrecer unia respuiesiá. Si ello es diferenciarse de responsabilidad, entonces, como enfatizó el Informe Scott, la veracidad, la amplitud (y también la oportunidad) de la disposición de la información es crucial.

\section{Desviando responsabilidad}

DowDing (1995:15j) usa el término desviando responsabilidad para calificar circunstancias donde el área política o institucional cae dentro del cometido de un ministerio, pero el ministerio declina proporcionar la información y desvía la solicitud: Ésta puede ser por mencionar al ministro o porque el ministro sugiera que la persona que ha solicitado la información, incluso si es un miembro del Parlamento, debe dirigir la solicitud al jefe ejecutivo de la organización, que es el que actualmente lleva el servicio, pretextando que es una materia operacional. A pesar de que DowDing no discute este punto, hay una posibilidad de que si el informe realizado por la persona a quien el investigador está remitiendo es insatisfactorio, exista un recurso al ministerio (para que lo lea otra persona más apropiada) con responsabilidad máxima en este sentido de la información proporcionada.

Responsabilidad como el reconocimiento formal de que la persona o cargo está al mando o control.

Las palabras entre comillas son de la definición de Chambers; en estricto sentido formal no implican directamente culpabilidad. La introducción de las Agencias Next Steps ha llevado a la identificación pública de los jefes ejecutivos al ser responsables de las operaciones de las agencias dentro del marco registral y de los planes anuales de su agencia; aunque, como veremos posteriormente, para algunas agencias la distinción entre responsabilidad formal para las materias políticas (una responsabilidad en sentido estricto, como explicamos anteriormente) de los ministerios y responsabilidad operacional de los jefes ejecutivos es difícil y quizás no tenga sentido hacerla. En la práctica, las personas en diferentes puntos de una cadena de responsabilidad, tendrán responsabilidad formal para diferentes aspectos del trabajo de una organización simultáneamente. Puede ser particularmente difícil separar la responsabilidad ministerial política, el marco registral y la asignación de recursos, de la responsabilidad operacional de los jefes ejecutivos. Aunque podemos concebir la responsabilidad formal como una condición en sí misma, en la práctica es más común estar asociada con al menos uno de los tres tipos siguientes: proclamación, explicación o justificación; responsabilidad modificadora; y concesión o aceptación de elogios o culpas.

\section{Proclamación, explicación o justificación}

DowDING (1995) se refiere a un sentido de responsabilidad como de "explicación o justificación`; el último implica ir más allá 
de simplemente una aceptación formal de responsabilidad, a otro nivel que admite más posesión sustantiva de responsabilidad.

\section{Modificación de la responsabilidad}

Este tipo de responsabilidad está señalado por DowDing y quizás pueda ser caricaturizado como: •no tenemos culpa pero aceptamos que algo se tiene que hacer. Si este tipo de responsabilidad es considerado como distinto, no implica más que una sutil distinción entre aceptación formal de responsabilidad —quizá por un hecho consumado o respuesta incontrolable y-o acontecinientos excepcionales - y responsabilidad que acepta eso, que no es culpable. La acción para arreglarlo necesita llevarse a cabo en el futuro con las mismas o similares circunstancias las cuales puedan ser cubiertas por una investigación de los acontecimientos bajo escrutinio. DowDING incluye un grupo de respuestas simbólicas a posibles investigaciones: castigos a los empleados individuales civiles, reorganización y cambio político.

\section{Inocente o culpable}

$\mathrm{Si}$ alguien es identificado por estar formalmente al mando o control es diferente que esa persona sea elogiada cuando la organización parece estar haciéndolo bien, a echarle la culpa si lo está haciendo mal. Esto puede presentarse de dos maneras, aunque en algunos casos se superpongan ambas:

(1) se acepta que hay factores fuera del control de las personas al mando;

(2) la culpa (o menos probable, el elogio) es concedida a una persona o personas identificadas por estar más directamente comprometidos en la actividad.

Ejemplos de (1) serían cuando una agencia interesada en absorber compañias fracasadas no encontrara su objetivo a través de una recesión. Los juicios de esta clase son raramente probables por estar claros, sin embargo, incluso si una organización no está encargada de acontecimientos que afectan su capacidad para cumplir el objetivo, chasta qué punto debería anticipar tales contingencias? El consentimiento de los ministerios para echar la culpa a los subordinados es vista por algunos comentaristas como una forma de socavar la naturaleza esencial de la responsabilidad ministerial y el papel del servicio civil.

\section{Premio o castigo}

La concesión de alabanza o culpa no produce por sí mismo una sustantiva recompensa o castigo a menos que la alabanza y la culpa se sientan como su propia recompensa o castigo. Las recompensas pueden tomar la forma de incentivos financieros, promociones, contratos renovados, etc... Los castigos pueden tomar la forma de pérdida de primas y dimisiones forzadas. En los Estados Unidos y en otros sistemas existe el proceso de incapacitación. Dimisión o destitución pueden ser vistas como la máxima aceptación o imposición de la responsabilidad sustantiva, aunque en el caso de los ministros las dimisiones pueden ser el resultado de actividades personales más que de la política o de la distribución de actividades de la que ellos son responsables. DowDING se refiere a sacrificio o responsabilidad punitiva. El término sacrificio implica un inmerecido castigo o al menos uno que podría ser compartido.

Puede valer la pena separar premios o castigos mientras se desempeña un cargo, de lo que DAY y KuEIN (1987:229) describen como responsabilidad en sentido estricto, que es la revocabilidad de un mandato.

Es importante advertir que los diferentes significados de responsabilidad pueden ser aceptados por un titular o pueden tener ese significado impuesto sobre ellos: Derek Lewis no aceptó que, como jefe ejecutivo del Servicio de Prisiones, fuera responsable en el sentido de ser culpable o castigable y, por lo tanto, pudiera ser despedido. El Secretario del Interior, mientras que aceptó que era necesario entregar un informe y tomar medidas, no consideró la culpa o el que pudiera dimitir, y finalmente no fue despedido.

\section{¿Responsabilidad, para qué?}

La responsabilidad puede no ser igualitaria: la misma persona puede tener diferentes tipos de responsabilidad con relación a los diferentes aspectos de actividades en una organización.

DAY y KLEIN (1987:24) sugieren que responsabilidad al asegurar ciertos criterios puede restar valor a la responsabilidad a personas particulares o puestos. En la práctica puede haber una mezcla. Entonces, el núcleo del debate en Inglaterra trata sobre si los empleados civiles pueden tener una responsabilidad hacia otro distinto que el gobierno actual.

De este modo uno puede imaginar en principio que:

* Responsabilidad para un aspecto particular como un valor absoluto, dejando aparte como podría ser verificado o aplicado.

* Responsabilidad para aspectos diferentes a actores diferentes.

Incluso un breve repaso a la historia de la responsabilidad indica en la práctica que responsabilidad para aspectos diferentes puede ser debida a diferentes personas o a través de itinerarios para cada persona, incluso si uno vuelve como DaY y KLEIN hacia la democracia directa ateniense.

Entre los aspectos operacionales por los cuales una persona u organización puede ser responsable destacan:

- por legalidad formal de gasto (tanto en términos de conformidad de intenciones y probidad, y evitación de corrupción); 
- por informe preciso de gasto y otras informaciones, incluyendo asuntos sobre si ha existido un cambio en la base por lo quie puieda sci juzgada si unia política está siendo dirigida correctamente;

- por eficiencia al usar los recursos;

- por eficacia en dos niveles:

- eficaz ejecución

- eficacia de diseño político en alcanzar resultados

- por proceder correctamente (evitar la mala administración);

- por correcta resolución de los asuntos;

- por atención al cliente (.calidad. de servicio antes que tratamiento sustantivo).

\section{La medida de requisitos de responsabilidad}

Un problema crucial de la responsabilidad al relacionarse con la autonomía es la medida de requisitos de responsabilidad en relación con la realización de tareas. Entre los problemas están los requisitos o expectativas de informar antes de pasar a la acción, y la habilidad formal o ade hecho. de la persona para la cual el informe es realizado para vetar o imponer una alternativa a la demanda propuesta. Ejemplos incluirían antedespachos de asistencia. Podemos distinguir entre asuntos donde un informe es ofrecido, y la persona a la cual el informe es entregado no tiene derecho de veto en la realidad; y aquellos donde la persona a la que el informe del asunto propuesto es entregado tiene el derecho de determinar la decisión actual. Ejemplo de lo anterior será la formal independencia legal de la Comisión Benéfica decidiendo sus acciones relacionadas con la caridad particular aunque informando al Ministerio del Interior; y el derecho de la Agencia de Carreteras para proceder a la expulsión de una persona mayor en el curso de la ejecución de una carretera mientras advertían al ministro, debido a la posibilidad de repercusiones políticas. Ejemplos donde en el antedespacho está sustantivamente incluido el papel del Secretario del Interior serían los casos de prisioneros particulares y del Secretario de Estado de Industria en decisiones sobre materias que él o ella han remitido a la Comisión de Monopolios y Fusiones.

Otro asunto interesante relativo a la medida de responsabilidad es si, un departamento o ministerio ve la contestación propuesta por un jefe ejecutivo de una agencia u otro cuerpo para entregar a un miembro del Parlamento o a otra persona, tiene el ministro el derecho o la capacidad de hecho para vetar o rehacer la solución propuesta. Este asunto se estudiara empíricamente más adelante en este documento.

\section{¿Responsabilidad a quién?}

DaY y KLEIN (1987:10-15) muestran que en los modernos Estados desarrollados del bienestar, tanto el número de personas a quien un informe tiene que entregarse como la complejidad de los vínculos crecen. No es simplemente una cuestión de una organización haciéndose más responsable que otra persona u organización, es que cada actor de alguna manera es responsable más o menos de unos y otros, directa o indirectamente. Los actores pueden ser responsables de maneras diferentes de aspectos distintos de su trabajo. El cuadro parecerá diferente dependiendo de los particulares arreglos constitucionales y las estructuras de distribución política en los diferentes países; pero en todos los países desarrollados contaríamos con un modelo complejo. La significación de cada tipo de vinculo -el ministerio, el cliente, los tribunales-cambiarán para agencias diferentes.

El problema de la responsabilidad ppor quién. es al menos tan importante como el problema de responsabilidad "para quién. El debate tradicional en Inglaterra sobre responsabilidad ministerial tiene que ver en parte con la responsabilidad de los servicios civiles por los ministerios al Parlamento. Para las agencias los problemas surgen de saber qué extensión debe tener su responsabilidad y en qué dirección debe ser encaminada, por ejemplo, las agencias de pensiones por servicios civiles (tanto agencia con vínculo oficial y secretarías permanentes) o por ministerios; o si, en efecto, la responsabilidad en la práctica debe estar en el punto intermedio antes que en el oficial, ya que es el máximo beneficiario de los informes de actividades.

\section{El modelo estándar Next Steps}

Las agencias ejecutivas están fundadas en una separación nominal de política y materias operacionales dentro de los departamentos. El gobierno aceptó las recomendaciones del Informe IBBS de que ulas agencias debian ser establecidas para realizar las funciones ejecutivas del gobierno dentro un marco político y de recursos establecido por un departamento. (Unidad de Eficiencia, 1988:9). El supuesto era claramente el siguiente:

La estrategia más importante de control debe recaer en el Ministro y el Secretario Permanente. Pero una vez establecidos dentro del marco los objetivos políticos y presupuesta- 
rios el director ejecutivo de la agencia debe tener tanta independencia como sea posible para decidir cómo son conseguidos estos objetivos... la presunción debe ser que, siempre que el gerente esté actuando dentro de la dirección estratégica reservada para los ministerios, se le debe dejar tan libre como sea posible para dirigir dentro de esta organización (Unidad de Eficiencia, 1988:9).

La idea, según palabras de Peter KEMP, que hay detrás de las Next Steps es resencialmente un concepto muy simple, en algunos sentidos casi ingenuo (HC 313-III, 1996:107). O como Derek LEWIS señala más gráficamente, el concepto de status de la agencia •no es una ciencia ascendente, son los principios básicos más simples de la gerencia (HC 313-III, 1996:94, q. 606). Las agencias son simplemente acuerdos administrativos dentro de los departamentos; las funciones ejercidas por las agencias son concedidas en el departamento y no en la propia agencia, de modo que la división de responsabilidades entre agencias y departamentos es determinada por el Acuerdo Marco y no por estatuto (ver HC 313-II, 1996:35).

El personal de las agencias está formado todavía por empleados civiles, trabajando bajo las condiciones y los términos del servicio civil, financiado por las finanzas públicas y responsable a través de los ministerios en el Parlamento (KEMP en HC 313-III, 1996:107), con las no insignificantes excepciones de los militares y otro personal civil que también trabaja en agencias, un elemento ignorado al confinar el debate de las agencias en cuestiones de relaciones ministeriales del servicio civil. La delegación de tareas y la extensión de las competencias gerenciales de los jefes ejecutivos es trazada por el Acuerdo Marco. La expectativa anunciada oficialmente es que, una vez la autoridad ha sido delegada efectivamente, los ministerios se retiren. de las materias operacionales, las rutinarias materias diarias que no tienen implicaciones en política general (Brazjer en HC 313-II, 1996:11). En este sentido podría haber una edespolitización. de las materias operacionales, pero la extensión de la despolitización está limitada en la práctica por la responsabilidad general de los ministerios ante el Parlamento.

En suma, para el inicial Acuerdo Marco, las agencias están sujetas a ciclos de cinco años de revisiones de .Opciones Preferentes", así llamadas porque incluyen consideraciones sobre si las actividades no deben continuar, o deben ser privatizadas $u$ organizadas de forma diferente. Si la decisión es continuar la actividad como una agencia, se prepara un nuevo Acuerdo Marco.

Hay también planes anuales corporativos, algunos de los cuales se mantienen confidenciales para la agencia y los departamentos por razones comerciales, y se presentan además informes anuales ante el Parlamento. Un elemento anual importante es la fijación de objetivos por indicadores de resultados, publicados en la evaluación anual consolidada de los Next Steps.
Así, el oficialmente anunciado modelo es uno de separación de política, ejecución y actuación dentro de un Acuerdo Marco que especifica los roles del ministro, el departamento principal y el jefe ejecutivo de la agencia e informa acerca de los objetivos anuales. Dentro del supuesto en el que el jefe ejecutivo tiene autonomía operacional, hay que advertir que se mantiene la responsabilidad ministerial.

\section{¿Qué significa esto en la práctica?}

Lo que significa en la práctica puede ser considerado bajo el apartado de compromiso ministerial, responsabilidad para el Parlamento, responsabilidad para promover el departamento, las operaciones de la agencia, la autonomía financiera, la autonomía de la organización y autonomía política.

\section{Compromiso ministerial}

El modelo simple puede implicar compromiso ministerial sobre unas bases anuales en la fijación de objetivos, aprobación de plan y evaluación de actuaciones de años anteriores. Un indicador de tal compromiso es la frecuencia de reuniones entre el jefe ejecutivo y el Secretario de Estado (ver Apéndice 1, columna final). Una vez más las variaciones son extremas, que van desde 43 reuniones en el caso del Servicio de Prisiones a ninguna reunión en el caso de muchas agencias.

Hay también diferencias estructurales en el enfoque presentado por los diferentes status de las agencias. Algunas agencias, como el Servicio Oficial de Topografía, no hacen formalmente informes a través de empleados civiles en el departamento principal del ministerio, pero sí directamente al ministro. Esto le proporciona el mismo nivel que a otros departamentos no ministeriales. Otras grandes agencias informan a través del Secretario Permanente, mientras las agencias más pequeñas pueden tener como contacto principal a un servicio civil de rango más bajo o a un consejo del departamento. Para las agencias relacionadas con el Ministro de Defensa hay una cadena específica de mando, que supone a menudo oficiales militares, a través de las agencias grandes y pequeñas que informan.

El manejo de las respuestas a las cuestiones parlamentarias proporciona otro indicador de la variabilidad en los procedimientos que afectan a los ministerios y agencias (ver lista en HC 313-Y, 1996:xliii). Las investigaciones de Tony WRGHT sobre si los ministerios habían modificado las respuestas de los jefes ejecutivos demostró una clase de sistema de escoger-y-mezclar: algunos lo tenían, otros no, mientras algunos tenían grandes fi- 
guras, otros tenían pequeñas figuras (HC 313-11I, 1996:p.160, q. 930). Lo que intentaba descubrir como un punto básico alrededor de responsabilidad, será equién tiene las respuestas?. lä respuesta es que en el final de la gama están las agencias donde las cuestiones políticas son contestadas exclusivamente por los jefes ejecutivos y que son invisibles para los ministerios antes de su finalización (Irlanda del Norte); y en el otro lado están las agencias en las cuales los ministros aprueban. rutinariamente las contestaciones de los jefes ejecutivos (Transportes). Sin embargo, la diferencia manifestada oficialmente es encontrarse entre diferentes departamentos ministeriales y, para la mayoría, el patrón utilizado es que el ministro puede ver una copia del asunto en el que normalmente no intervendrá (HC 313-Y, 1996:p.xliii). Hay una evidencia no sistemática disponible acerca del diferente tratamiento manifestado dentro de un departamento en relación con las características de la agencia o su visibilidad. De este modo, ni hay un patrón constitucional acerca del papel de los ministros en relación con los jefes ejecutivos para contabilizar las materias operacionales, ni un intento sistemático para estructurar tales relaciones sobre la base de especiales características o sensibilidades de agencias individuales.

\section{Demandas de informes por los parlamentarios y el Parlamento}

Las agencias llaman la atención de los parlamentarios desigualmente. Nuestro análisis sistemático del alcance parlamentario de las agencias, utilizando la base de datos POLIS, demuestra que, en términos cuantitativos, las cuestiones parlamentarias escritas son abrumadoramente el principal modo registrado que los parlamentarios utilizan para llamar a las agencias a informar sobre mecanismos parlamentarios formales. De un modo parecido las cartas de los parlamentarios a los ministros, proporcionadas tradicionalmente por un coste eficiente y efectivo, pretenden avisar a los ministros de los intereses de los parlamentarios. Tomadas juntas las cuestiones parlamentarias y las cartas proporcionadas por los parlamentarios, son en términos cuantitativos el más sistemático indicador formal del interés colectivo de estos parlamentarios en las acciones ejecutivas.

Las agencias llaman con distintos números a las cuestiones parlamentarias (ver Tabla 1) y a las cartas de los parlamentarios (ver Apéndice 2). Desde noviembre de 1992 las cartas enviadas por los jefes ejecutivos de las agencias a los parlamentarios en respuesta a las cuestiones planteadas han sido publicadas diariamente en el Registro Oficial, con una declaración estándar del ministro con responsabilidad de la agencia. Como informaba el entonces líder de la Cámara, Tony Newton, a los parlamentarios (HC Debates 20 de octubre 1992, vol 212, col.) 287-8w), uLos acuerdos responden a cuestiones presentadas en las materias operacionales, en las cuales la responsabilidad ha sido delegada por los ministros a los jefes ejecutivos de las agenciasn. Unas pocas agencias, en consecuencia, atraen más cuestiones y proporcionan más respuestas directamente de sus jefes ejecutivos que otras. Media docena de agencias pueden ser identificadas como el epez grando nádando en las aguás más cercanas a las opiniones e intereses de los parlamentarios; en un nivel intermedio están una media docena más, que está en los niveles más bajos del interés parlamentario,y en las oscuras profundidades se encuentran una multitud de agencias, las cuales atraen muy poco y en algunos casos nada el interes parlamentario en un período de tres meses.

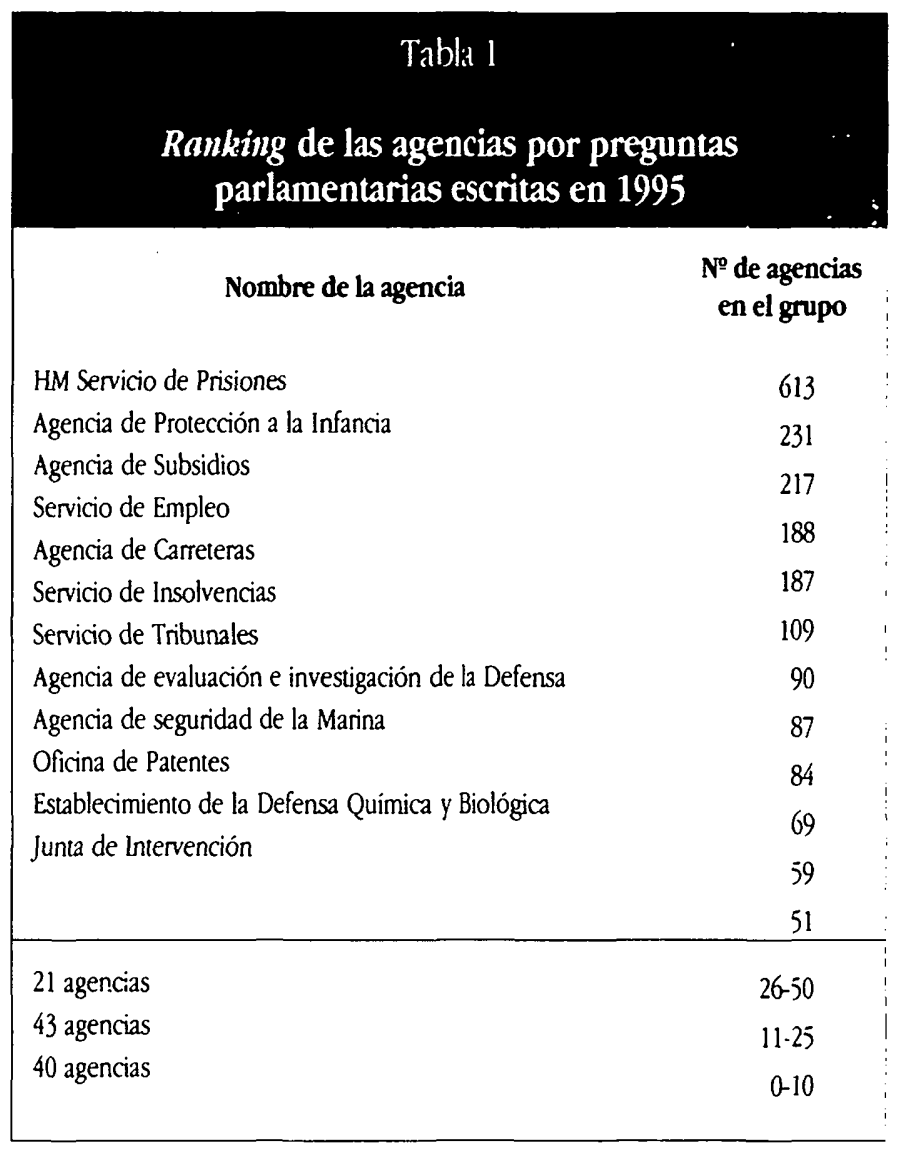

Fuente: Autores, datos obtenidos de la base de datos del Parlamento CD-ROM (POLS).

Notas: Excluidas las cifras del HMSO y de la Oficina Central.

Este modelo se repite si examinamos las cartas de los parlamentarios y los jefes ejecutivos (Apéndice 2). De nuevo, el Servicio de Empleo, el Servicio de Prisiones, la Agencia de Subsidios y la Agencia de Protección a la Infancia están en el primer plano de las preguntas parlamentarias, mientras la Agencia de Pensiones de Guerra atraía también más de 1000 escritos. Un grupo de 8 agencias atraía niveles intermedios de atención, entre 101 y 1000 escritos, 32 recibian entre 11 y 100 , seguidos por 38 agencias que recibían solamente entre 1 y 10 escritos en un año. 34 agencias no recibían ninguna correspondencia de los parlamentarios.

El requisito de contestar a las preguntas de los parlamentarios nos lleva claramente al modelo tradicional de responsabilidad frente al Parlamento, en vez del "sencillo" modelo explícito 
en el modelo Next Steps. Nuestra investigación revela un cuadro variado en términos de si el requisito de contestar es visto por las agencias u observadores de ellas como positivo o patológico. Para la mayoría de agencias parlamentarias la responsabilidad no es ni un problema real ni un problema. Lo característico de las respuestas en nuestras entrevistas era:

Las preguntas parlamentarias son una parte normal del proceso democrático (un regulador NDPB)

Basta decir aquí que no es un problema nuestro. En general, si el departamento necesita alguna información adicional para responder una cuestión, nosotros podemos proporcionarla bastante rápida y eficientemente. No es un gran problema para nosotros. Nosotros no tenemos a nadie especificamente dedicado a esto y tampoco dedicamos mucho tiempo a ello (única industria NDPB).

Yo no tengo el menor inconveniente en que los parlamentarios escriban sobre mí, tanto quejándose como preguntándome cuestiones, yo estoy contento de contestarles (regulador NDPB).

Estos comentarios repetían la opinión de Lawrie Haynes, jefe ejecutivo de la Agencia de Carreteras, que respondía a la pregunta "Piensa que contestar preguntas a los parlamentarios... ocupa demasiada parte de su tiempo?»:

No, yo no lo veo de ese modo. Creo que hay algunas preguntas legítimas entre las que llegan...

Encuentro eso muy útil. Es realmente un buen mecanismo para el personal estar enterados de la preocupación de la gente por sus acciones (HC 313-v 1996:86).

Las agencias generalmente contestan diligentemente las cuestiones parlamentarias. Una persona entrevistada llamó la atención sobre la importancia que supone que las respuestas sean rápidas, "porque no hay nada más vergonzante para un ministro que habiendo un miembro de la agencia en la sesión tener que responder a una pregunta sobre algo a lo que la agencia no tiene obligación de responder" (Agencia de Irlanda del Norte).

Pero, generalmente, otros comentaristas (ver, por ejemplo NorTON en HC 313-II, 1996:74), han observado que las respuestas de las agencias a las cuestiones de los parlamentarios tienden a ser más extensas que las recibidas directamente por los ministros, también son más propensos a expresarse con esperanza de que las preguntas ayuden $y$, en algunos casos en realidad a disculparse de errores de hecho o inexactitudes en los que incurren $\rightarrow$ una respuesta no se asociaría con la tendencia normal de las preguntas de los departamentos (NorTon en HC 313-II 1996:74). En cuyo caso los beneficios positivos parecen proceder de las agencias y el Parlamento, igualmente en la contestación de las preguntas parlamentarias por los jefes ejecutivos.
Sin embargo, para algunas agencias existen importantes perjuicios de organización asociados con las respuestas a las preguntas parlamentarias. Irónicamente los periuicios son experimentados e identificados en las menores y menos visibles agencias, además de en las mayores y más visibles. Un jefe ejecutivo de una agencia muy pequeña, con recursos de personal limitados, se quejaba de estas cosas:

- Cuestiono el uso de las preguntas parlamentarias, en términos de tiempo, dinero y esfuerzo. Nosotros gastamos una buena cantidad de tiempo consiguiendo información, lo cual como un contribuyente ordinario no puede ver el beneficio de... Pienso que si el público corriente fuera más consciente del tiempo dedicado a las preguntas parlamentarias, no estarian muy contentos del tiempo y dinero público gastado" (pequeña agencia Next Steps suministradora de servicios a los marginados)

Lo que particularmente ofendía a este entrevistado es el fenómeno de la "pesca de preguntas" de un diputado, con un interés general en fijar los antecedentes educativos de los empleados públicos (ver por ejemplo HC Debates 13 de marzo de 1998, vol. 307, cols. 383-9) o los gastos en investigación de mercado del gobierno central (ver HC Debates del 18 de febrero de 1998 vol. 305, cols. 89-51), preguntando lo mismo a todos los departamentos y agencias sin estar expresamente interesado en el trabajo de ningún departamento o agencia en concreto. En efecto, el mencionado jefe ejecutivo hizo referencia con arecibes ridiculas peticiones como cuantas matriculas privadas... pienso que el último tenía que ver con la diversión. En estos casos de responsabilidad parlamentaria era vista como un perjuicio de la posición de la agencia.

De más trascendencia es, sin embargo, el aparente cambio organizativo dentro de unas pocas agencias de alto perfil tratando con los conflictos políticos o las materias delicadas. Claramente, la necesidad de responder a las preguntas parlamentarias y de ser sensible de la responsabilidad de los ministros ante el Parlamento, ha tenido un impacto organizativo en esas agencias -políticamente sensibles", del alcance de crear grupos parlamentarios especiales y grupos, en algunas. La gran cantidad de preguntas parlamentarias y la implacabilidad con la que éstas son seguidas puede tomar proporciones patológicas. Antes de examinar ese argumento, sin embargo, podría ser reiterado que para la aplastante mayoría de agencias el examen parlamentario no es percibido como causa de problemas organizativos. De las respuestas típicas de las agencias de medio-rango (en términos de volumen de cuestiones parlamentarias) un director de NDPB observa lo siguiente: "nosotros tenemos un par de personas que ahora tratan con los parlamentarios con más o menos dedicación plena. Ellos están despejados en el máximo nivel dentro de la organización. 
Para otras agencias, en particular el Servicio de Prisiones, la Agencia de Protección a la Infancia, la Agencia de Subsidios y el Servició de émpleo, el inierés persisistente de los diputados en sus actividades cotidianas ha tenido consecuencias organizativas. De nuevo se necesita que se repita que no todos estos efectos son patológicos en sí. De hecho, Michael Bichard, exjefe ejecutivo de la Agencia de Subsidios, observó que por el tiempo en que él abandonó la agencia estaba firmando el $80 \%$ de las respuestas a las cartas de los diputados y que esto era verdaderamente beneficioso porque conseguía una visión de conjunto de la agencia al examinar la abrumadora mayoría de las preguntas, quejas y sugerencias que estábamos obteniendo de los diputados (HC 313-III 1996:160). Armado con esta información sentía que estaba bien colocado para evaluar la ejecución y además para plantear algunos de los problemas que teníamos en la organización. en el encuentro mensual entre los jefes ejecutivos y los ministros.

La gran cantidad de preguntas de los parlamentarios condujo a la creación de un grupo parlamentario en el centro de la Agencia de Subsidios. Los directores locales informaron a este grupo y se refirieron a: los problemas que estaban surgiendo más de una vez o eran seriamente conflictivos" (HC 313-III, 1996: 160). El ex-jefe ejecutivo de la agencia señaló que era costumbre enviar periódicamente consejos de los diputados sobre cómo podían obtener las mejores respuestas a sus preguntas con ponerse en contacto con oficinas locales en primer lugar, o, si era sobre temas muy diversos organizativamente, se les recomendaba contactar antes con el jefe ejecutivo que con el ministro. Este consejo parece que se ha tenido en cuenta porque en 1995 el 65 o $70 \%$ de las cartas parlamentarias estaban dirigidas directamente al jefe ejecutivo antes que al ministro.

El impacto de las continuas preguntas e interrogaciones por parte de los parlamentarios sobre la estructura organizativa de las agencias es también evidente en la Agencia de Protección a la Infancia. El Departamento Especial tuvo que ser creado en 1993 en respuesta al volumen excepcional de correspondencia -más de 5000 cartas en un año- directamente a Ros Hepplewhite (entonces jefe ejecutivo). El Informe Anual de la Agencia de 199394 advertía de la introducción de un -nuevo sistema que rastrea y controla el gran volumen de cartas que estamos recibiendo de los parlamentarios (Agencia de Protección a la Infancia, 1994:14). Esto motivó la creación de una Unidad especial de Correspondencia Parlamentaria (PSU) en la Oficina Central de Londres para ocuparse de las cartas de los parlamentarios. Al cabo de un año esta Unidad se expandió y se creó una nueva base de datos para mejorar la calidad y rapidez de las respuestas a los parlamentarios. En 1994-95 preparó respuestas a 12.374 cartas de los parlamentarios y los Centros de la Agencia de Protección a la Infancia (CSAC) de todo el país también contestaron alrededor de 100 cartas en una semana (Agencia de
Protección a la Infancia, 1995:12). En 1996-97 los directivos de la Oficina de Comespondencia Parlamentaria y los Centros de la Agencia de Protección a !a Infancia prepararon más de 17.900 respuestas a las cartas de los parlamentarios. Al principio de año solamente el $30 \%$ de la correspondencia parlamentaria se despachaba dentro del plazo estipulado por el departamento que era de 20 dias. En total para 1996-97 el término medio estimado de contestación de 20 días mejoró en un 78\% (Agencia de Protección a la Infancia, 1997:16).

El impacto organizativo por la necesidad de respuesta a las preguntas de los parlamentarios y ser sensibles hacia una responsabilidad ministerial hacia el Parlamento puede ser visto en estas agencias •políticamente sensibles. Sin embargo, los efectos organizativos patológicos - procedentes de la tensión entre, por un lado, las materias organizativas, eficiencia y distribución de servicios; y por otro, materias políticas, responsabilidad y sensibilidad política - están mejor demostradas en el caso del Servicio de Prisiones, según el Director de Transportes Derek Lewis. El antiguo director general encontraba difícil cuantificar el impacto exacto de contestar directamente las peticiones de informes de los parlamentarios, pero no había duda que el nivel de compromiso detallado y suministro de información... ciertamente era una distracción. (HC 313-v, 1996:99). El Informe Learmont (1995) - una revisión del servicio de seguridad de la prisión como consecuencia de la fuga de la Prisión Parkhurst el 3 de junio de 1995- también llama la atención sobre la tensión percibida entre eficiencia y responsabilidad.

El Director General es requerido para ocuparse de un gran número de preguntas parlamentarias, cartas de los parlamentarios y cuestiones parlamentarias. Éstas rondan ahora un total de casi 600 cuestiones por año, algunas de las cuales riccesitan discusión con los Ministros para conseguir una contestación mutuamente aceptable, y 4.000 cartas de los parlamentarios. El Director General no había asumido esta tarea voluntariamente: les es asignado como a los jefes ejecutivos de todas las agencias.

En el caso del Servicio de Prisiones responsabilidad informativa fue identificada como un eproblema. y Learmont recomendó que El problema de la preocupación de los directores generales con las materias parlamentarias debe ser superado. Debe corregirse el equilibrio de mantener informados a los ministros y funcionando el servicio (CM 3020 1995:110). Para Derek LEWIS, sin embargo, el problema nunca fue superado y simplemente se abandonó a quejarse cada mañana cuando nos enfrentábamos al montón de cartas• (LEWIS, 1997:69).

En las investigaciones de la oficina de Intervención Nacional, cuyos informes van directamente al Parlamento, ha habido un foco de fricción tanto por el tipo de información solicitada como por los recursos que se dedicaban a hacer frente a la investigación. La publicidad hostil proveniente de los informes 
del Comité de Estado de Informes Públicos, tales como los de la Agencia de Protección a la Infancia, pueden haber sido apenas una forma agradable de publicidad en un momento en el que la agencia estuvo bajo una enorme tensión. Para otras muchas agencias, sin embargo, los resultados de las extensísimas investigaciones de los comités de investigación departamental son mucho menos negativos. En efecto, hay evidencia de que hay agencias que están deseosas de usar informes de los comités para apoyar sus reclamaciones con el fin de llegar a sus objetivos fijados. De este modo, por ejemplo, el Informe Anual del Servicio de Prisiones de 1996-97 (HC 274, 1997) dedicaba una página entera del informe del Comité del Ministerio del Interior sobre gerencia en el servicio de prisiones. La página fue sacada con referencias de las alabanzas" de los diputados por los "enconiables progresos" dentro del servicio y por las "elicitaciones" brindadas en el informe por las reformas en el servicio de entrega ( $\mathrm{HC}, 274$ 1997:15). En el prefacio del Informe Anual, Richard Tilt, Director General expresó su eplacer de que un grupo multipartidista de diputados alabara muchísimo el trabajo del servicio de prisiones". Desde luego en este caso, al menos, la responsabilidad exterior no fue percibida en absoluto como negativa.

\section{Responsabilidad de los departamentos}

Claramente, algunas agencias atraen más los intereses parlamentarios y públicos que otras. Eso nos llevó a preguntarnos en un estado inmaduro de la investigación, cuando sólo habíamos examinado indicadores aprovechables de compromiso con los diputados y los ministros, por el significado en la práctica de responsabilidad cuando no hay o son pequeños los intereses ministeriales de los parlamentarios durante un periodo de un año, especialmente dado el papel central que a la responsabilidad de los ministros ante el Parlamento se da en el modelo británico (JUDCE, Hogwood y MCVICAR, 1997). Nuestra posterior pero todavía incompleta investigación que arranca de las entrevistas con funcionarios de las agencias y otros grupos en el centro de sus departamentos ha establecido que la ausencia de interés ministerial y parlamentario no implica ausencia de responsabilidad. Incluso aquellos menos sometidos a las cuestiones de los diputados o a las reuniones con ministros están, sin embargo, dispuestos a informar y a someterse al escrutinio, en particular en el centro de los departamentos pero además por sistemas externos de evaluación.

Un grupo de funcionarios nos comentaba en las entrevistas que estaban decepcionados con su posición en la agencia y con la falta de autonomía:
•Mi entendimiento de la posición en la agencia era que tú podias tener una cierta cantidad de autonomía para hacer y dirigir los asuntos. Que parece ser menos y menos... y cada vez parece ser más legal. Podríamos realmente hacer cosas mucho más eficientemente si nos hubieran permitido entrar en el tema pero, al estar todo tan reglamentado y regulado, lo hace realmente más ineficiente y exige mucho tiempo. La cantidad de trabajo administrativo que tengo que rellenar.... (pequeña agencia Next Steps suministradora de servicios a marginados).

- Pienso que es contrario a lo que debería ser el proceso de las agencias Next Steps. Lo que digo es que somos controlados por nuestro rendimiento por objetivos y es auditada financiera y técnicamente. Las Agencias Next Steps fueron creadas para ser imparciales, autónomas, unidades auto-posicionadas que pudieran ser controladas desde lejos y que las dejaran progresar. No nos dejan progresar. Hay cantidad de interferencias y de formularios por rellenar. (Agencia Next Steps de Agricultura que se ocupa de la regulación).

Una fuente particular de quejas era la repetición de solicitudes de información, así como la acumulación informativa en todos los departamentos. Uno de los asuntos planteados desde la perspectiva de las agencias es que algunas demandas de responsabilidad son hechas sin relación con otras, lo que provoca una posible coincidencia de los requisitos de responsabilidad. Por ejemplo, una unidad de investigación podría ser evaluada para medir su excelencia investigadora, siguiendo criterios docentes y a pesar de conseguir un buen resultado, estar sujeta a una revisión gubernamental interna con el fin de valorar su viabilidad como centro de investigación. De este modo, una agencia puede tener que informar de varias formas diferentes de algunos aspectos de sus actividades.

Relacionada directamente con esta redundancia es la percepción de que las agencias están teniendo constantemente que mostrar idoneidad de procedimientos o resultados sustantivos. Habría escasas quejas si tales exámenes estuvieran limitados al examen anual de objetivos, al marco del proceso y al ciclo de cinco años de análisis de "opciones preferentes" (a pesar de que algunos ejecutivos consideran que, siendo responsables de los trabajos de cambio organizativo cada cinco años, es bastante drástico). Sin embargo, las agencias están modificando etapas constantemente, siendo propensas a las revisiones departamentales, revisiones de todo el sistema (alguna vez como estudios de caso), revisiones especiales de determinadas categorías funcionales de grupos tales como centros de investigación, pruebas de mercado, investigaciones de la Auditoría Nacional, etc.

El Servicio de Prisiones es único en la perpendicular escala de peticiones para dar un informe (seguido por algunos puntos por la Agencia de Apoyo a la Infancia). Sin embargo, estas peticiones estaban en su mayor parte concentradas en el citado 
parlamentario, el -propio- ministerio y las demandas departamentales. Para otras organizaciones -con una escala de niveles de demandas parlamentarias - es la absoluta multiplicidad de los orígenes de las demandas lo que les causa problemas.

Además del departamento que las patrocina, tal como algunos tipos de clientes o grupos científicos, se resienten de las mayores demandas de información que les llegan, frecuentemente o al azar, de otras fuentes.

\section{Las agencias y la autonomía financiera}

En términos de autonomía financiera de las agencias, el modelo varía considerablemente con variaciones a lo largo de toda la escala de financiación, desde el 100\% de financiación de sus actividades para cubrir completamente todos sus costes de cuotas o precios. Relacionado con esto se encuentra la diferencia en términos comerciales, con tres categorias principales:

* Fondos financiados con dinero votado en el Parlamento. Teniendo que ser pagado con fondos del gobierno central cualquier gasto generado. En octubre de 1996 , dos tercios de las agencias estaban operando con esa base, la base tradicional de la contabilidad gubernamental (Consejo de Ministros, 1996).

* Los "gastos corrientes netos" de las agencias están financiados con fondos gubernamentales, pero pueden quedarse con ingresos por compensaciones de costes de operaciones. A finales de 1996, menos de un cuarto de agencias estaban operando en esta base.

* La última categoría son "Jos fondos comerciales", los cuales dependen completamente de fondos obtenidos para sus gastos. Esto ocurría en octubre de 1996 con 14 de 125 agencias.

La última categoría es claramente la que con probabilidad tenga mayor autonomía. Un miembro de una agencia oficial nos explicó en una de las entrevistas a a menos que tengas un fondo comercial, estás sólo jugando a ellow. Incluso dentro de esta categoría podemos encontrar una distinción entre las agencias que dependen completamente o en su mayor parte de contratos con su departamento central y las que generan sus fondos de otras fuentes.

Los mecanismos de responsabilidad financiera son, por tanto, un aspecto importante de las relaciones de las agencias con el departamento central y con el Tesoro. Cada agencia (y otras corporaciones) es, ante su ministerio, responsable de sus gas- tos. En el caso de las agencias N'ext Sieps, a cada ur.. se le exige presentar un informe anual con informes auditados, los cuales se presentan ante el Parlamento. La mayoría también produce programas corporativos públicamente disponibles (excepto en agencias donde hacer eso sería comercialmente perjudicial). Queda claro por nuestra investigación que el grado del departamento central en los compromisos e interferencias en las materias financieras es anómalo. Algunas agencias informan acerca de pequeños contactos con el departamento a un nivel financiero, más allá de los informes básicos (los cuales pueden ser dirigidos mensual, trimestral o anualmente). Otros no fueron tan afortunados. En algunas agencias que generaron parte pero no todos sus ingresos había resentimiento porque los requisitos de la contabilidad pública clásica les habían sido aplicados al conjunto de sus fondos incluyendo los autoproducidos, como demuestra esta cita:

Gastar más o menos según el presupuesto es correcto. Pero gastar menos de lo previsto, desde varios puntos de vista, plantea preguntas. Aunque somos una agencia, cerca del $30 \%$ de nuestro negocio es de carácter comercial. En términos de responsabilidad, ésta es una cuestión clave. El “departamento" por estar totalmente implicado en ello no tiene idea. Estos tipos han hecho sus carreras enteras en el servicio civil, tienen una buena perspectiva convencional basada en el voto y tienen un camino simplista de sumar números y un desconocimiento general de las necesidades de un negocio. Tenemos que ser flexibles y adaptables pero también tenemos que conocer todo el criterio contable del gobierno... En términos de responsabilidad, con el 30\% de nuestro negocio de carácter comercial, siento que sólo el $70 \%$ de la responsabilidad es comprendida por aquellos que observan nuestros asuntos. Se ven las cosas en términos simples. Nosotros, como una agencia que lleva más que un sustancial EYF (final año flexible), necesitamos consentimiento para la nómina del siguiente año financiero. En lugar de eso ser aceptado como thas generado el dinero, tienes buenas razones para necesitarlo el año siguiente... cada año tenemos que discutir porque tenemos ese dinero con el departamento. No hay ocasión de ir aprendiendo poco a poco con el departamento porque siguen cambiando el personal (una herencia de la agencia Next Steps).

Aquellos que esperaban conseguir mayor autonomia mediante corporaciones públicas no departamentales (NDPB), categoría fuera del servicio civil, están decepcionados:

La Memoria financiera incluye un número de delegaciones que tenemos en el departamento. Por ejemplo, a nosotros no nos permiten comprar, ser dueños de propiedades de ninguna clase sin consentimiento del departamento. Así, claramente, incluso si necesitamos firmar un contrato sobre un pequeño terreno cerca de nuestras propiedades para poder 
añadir un bloque de lavabos, por un millar de libras, habría tenido que tener aprobación del departamento por si acaso en la negociación tengamos que celebrar encuentros, discusiones o documentos. $Y$ en cualquier momento ocurren muchas de estas cosas (un legado NDPB).

La discusión con funcionarios en cada organización reveló interesantes diferencias de perspectivas, por un lado, las de aquellos con antecedentes de servicio civil tradicional y, por otro, de las de los que procedían de fuera del servicio civil. Un número de directores financieros (que habían sido reclutados del sector privado) tenían perceptibles perspectivas diferentes en los procedimientos administrativos contables al de sus jefes ejecutivos. Los de fuera del servicio civil (especialmente directores financieros) a menudo expresaban impaciencia con la responsabilidad del sector público y los procedimientos contables. Aquellos con antecedentes en el servicio civil están en general más preparados para aceptar éstos como modelo de trabajo para las organizaciones del sector público.

Una diferencia nueva importante es entre aquellas agencias que tienen la categoría de departamentos independientes no ministeriales, que tienen relaciones directamente con el Tesoro en materias presupuestarias, y las agencias que son parte de los departamentos ministeriales que aún en su mayor parte tienen relaciones con materias financieras a través de la división de finanzas del departamento central.

\section{Las agencias y la autonomía organizativa y de personal}

El proceso de creación de las agencias ha estado sin duda acompañado de un aumento de la facilidad con la que los jefes ejecutivos han sido capaces de tomar decisiones acerca de la estructura de la organización, ubicación de los funcionarios y otros servicios, empleos de personal, calificaciones y remuneraciones. Antes, algunas de estas flexibilidades eran posibles en principio, pero tenian que estar sujetas a delegaciones específicas por los departamentos centrales. Inicialmente, esto producía una diferenciación adicional de las agencias. Desde el 1 de abril de 1994 las agencias mayores asumieron responsabilidades para negociar sus propias remuneraciones. Para abril de 1995, 29 agencias y los dos departamentos de ingresos habían tomado responsabilidad delegada para sus propias remuneraciones y otros pagos - relacionados con las condiciones del servicio (Consejo de Ministros, 1996). Desde el 1 de abril de 1996 la responsabilidad sobre las remuneraciones y las calificaciones del personal por debajo de la categoría superior fue delegada a todos los departamentos, reemplazando los acuerdos actuales de remuneraciones nacionales, que se habían terminado. De este modo, el problema de la autonomía del personal no está hoy en día limitado a las agencias.

Sin embargo, han estado lejos de la autonomía completa (dejando a un lado el análisis de Anteriores Opciones del quinto año). Las agencias habían estado sujetas a un número de iniciativas del servicio civil nacional que habían limitado la autonomía de los jefes ejecutivos para cumplir sus servicios dentro del Acuerdo Marco; un ejemplo particularmente significativo fue la iniciativa de la Competencia por Calidad., por la que agencias y otras partes del servicio civil fueron requeridas para identificar parte de sus operaciones por la posibilidad de una posible competencia al contratar. Esta iniciativa causa resentimiento entre algunos jefes ejecutivos, quienes sentian que habiéndoles sido dada autonomía de organización ahora se les decía cómo ejercerla.

\section{Las agencias y la autonomía política}

Puede parecer que, de acuerdo con el modelo normal Next Steps, el problema de la autonomía política no se produciría, ya que están pensadas para ejecutar la política pensada por el ministro. En la práctica la separación esta lejos de ser completa (ver MARSEY, 1995:14-23). Así, algunas agencias, como el Servicio de Empleo, tenía escrito en su Documento Marco que el jefe ejecutivo pudiera ofrecer consejo al ministro y que debía ser consultado sobre las propuestas políticas que pudieran tener consecuencias para la agencia. En un caso extremo donde la agencia tiene un monopolio de conocimientos técnicos, como en el caso de la Agencia de Seguridad de los Pesticidas, la agencia puede ser el asesor político oficial del ministro. Éste plantea cuestiones interesantes sobre cómo el departamento central puede valorar los informes de una agencia. Puede haber también ambigüedad sobre informes acerca de futuras operaciones de una agencia, cuando la agencia además tiene el rango de departamento no ministerial, que no es parte del departamento principal del ministerio. Esto fue considerado como causante de problemas de un vacío de informes en un Informe del Comité de Asuntos Públicos en la privatización del HMSO (HC 599, 1998).

Sin embargo, mientras algunas agencias tienen autonomía para ofrecer informes políticos, dentro del servicio civil es normal la convención de que los informes son confidenciales. Una excepción parcial es cuando el jefe ejecutivo del Servicio de Prisiones y la Agencia de Carreteras han señalado públicamente las implicaciones de la política sobre sus recursos. Las Agencias 
no tienen una posición de veto políico y cuando el nuevo gobiemo laborista asumió su cargo en mayo de 1997 el jefe ejecutivo del Servicio de Empleo dejaba bien sentado con entusiasmo su deseo de cooperación con el programa de Trabajos de Asistencia Social antes que probar a seguir manteniendo el plan anual actual. Las Agencias tienen sustancialmente menos autonomía que algunas NDPBs, como el Registro de Protección de Datos, quien osó hablar públicamente sobre la necesidad de cambios legislativos, y los reguladores de la industria-simple quienes tienen la -autoridad para introducir cambios políticos dentro del sistema de la legislación actual, aunque de materias sujetas a apelación.

\section{Conclusión}

El modelo normal de las Agencias Next Steps, que se explicó claramente en la época de su presentación, no proporciona una descripción útil de lo que ha ocurrido en la práctica. Hay dos elementos en esto. Primero, hay una variación enorme en la práctica en el alcance de cuál de las diferentes agencias son llamadas a justificar sus actividades, en particular a los ministros y los parlamentarios. Éstas incluyen cuestiones sobre trabajo social con individuos y materias administrativas y no están desde luego limitadas a una consideración anual, hasta el punto de que los objetivos se hayan conseguido. Segundo, hemos establecido que incluso para pequeñas $y$, al parecer agencias técnicas, los tipos de escrutinio a las que están sujetas van a ir mucho más allá del simple modelo Next Steps. Una característica particularmente notable era los múltiples caminos que deben seguir las agencias y otros cuerpos para someterse al escrutinio. Esto no supone negar que ha habido incrementos en autonomía en el aspecto organizativo, en el personal y en menor grado en materias financieras. Una de las ironías es, sin embargo, que la mayor autonomía conseguida en las agencias de estas dimensiones, en particular en las financieras, lo más probable es que no continúen haciéndose como una agencia, ya que lo más seguro es que sean privatizadas.

\begin{tabular}{|c|c|c|c|}
\hline \multicolumn{4}{|c|}{ 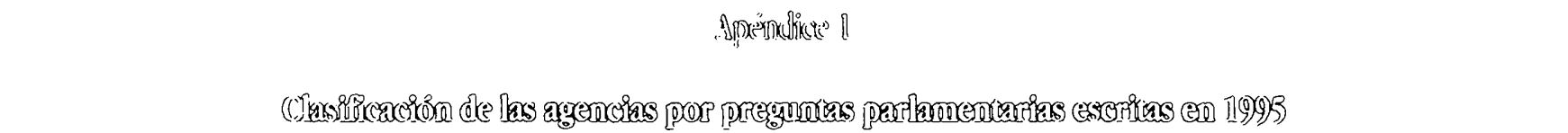 } \\
\hline Nombre de la agencia (1) & $\begin{array}{l}\text { N. } .^{2} \text { de preguntas } \\
\text { parlamentarias } \\
\text { escritas }\end{array}$ & Personal 1/11/95(2) & $\begin{array}{c}\text { N. } .^{9} \text { de reuniones } \\
\text { entre el Jefe Ejecutivo } \\
\text { y el Secretario de Estado }\end{array}$ \\
\hline Servicio de Prisiones de Su Majestad & 613 & 38.935 & 43 \\
\hline Agencia de Protección a la Infancia S.S. & 231 & 5.985 & (7) 0 \\
\hline Agencia de Subsidios de la S. S. & 217 & 66.650 & 12 \\
\hline Servicio de Empleo & 188 & 39.850 & - \\
\hline Agencia de Cameteras & 187 & 2.130 & 16 \\
\hline Servicio de Insolvencia & 109 & 1.500 & (6) 0 \\
\hline Servicio de Justicin & 90 & 9.845 & 1 \\
\hline Agencia de investigación y evaluación de la Defensa & 87 & (4) 11.680 & - \\
\hline Agencia de Seguridad de la Marina & 84 & 390 & 1 \\
\hline Oficina de Patentes & 69 & 885 & (6) 0 \\
\hline Fucrzas de Defensa Quimicas y Biológicas de la Defensa & 59 & - & - \\
\hline Junta de Intervención & 51 & 885 & Frecuente \\
\hline Oficina del Registro Público & 47 & 435 & 2 \\
\hline Servicio de Prisiones de Escocia & 47 & 4.235 & - \\
\hline Casas de Reposo & 46 & 945 & (6) 0 \\
\hline Servicio consultivo y de desarrollo agrícola & 46 & 1.850 & Frecuente \\
\hline Agencia de cotización a la S.S. & 43 & 8.900 & (7) 0 \\
\hline Agencia de Guardacostas & 43 & 535 & 1 \\
\hline Inspección de Vehículos & 42 & 1.485 & 0 \\
\hline Agencia de control de medicamentos & 38 & 345 & - \\
\hline Agencia de autorización de vehículos y conductores & 34 & 3.780 & 1 \\
\hline Agencia de nornas de circulación & 34 & 1.680 & 1 \\
\hline Registro Cittastral de Su Majestad & 34 & 8.510 & 2 \\
\hline Servicio de Planificación & 34 & 585 & 0 \\
\hline Laboritorio de Investigación del Transporte & 33 & 425 & 2 \\
\hline
\end{tabular}




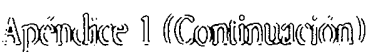

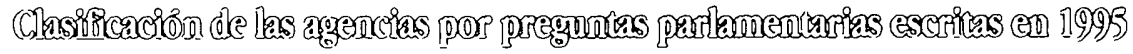

Nombre de la agencia (1)

Nombre de la agencia (1)

\section{N. de preguntas parlamentarias escritas}

Personal 1/11/95(2)
N..$^{2}$ de reuniones entre el Jefe Ejecutivo y el Secretario de Estado
Consejo de Medicinas Veterinarias

Servicio de Higiene Cámica

Oficina Central de Información

Agencia de Pensiones de Guerra

Laboratorio Nacional de Ingeniería

Inspección de Planificación

Centro Informático Cliessington

Laboratorio Central de Ciencias

Agencia de Empleo y Formación

Informes del Consejo General de Defensa

Agencia de Radiocomunicaciones

Oficina del Monopolio Público

Histórico de Escocia

Consejo de Seguridad de los Pesticidas

Laboratorio Nacional de Pesas y Medidas

Fundación de Investigación de Edificios

CADIV

Laboratorio Central Veterinario

Oficina de Tasación

Agencia de Pensiones del Sistema Nacional de Salud

Organización de Obras de las Bases del Ejército

Oficial Pagador de Su Majestad

Agencia de Palacios Reales Históricos

Laboratorio Nacional de Fisica

Agencia de Servicios de evaluación y selección

Escuela del Servicio Civil

Servicio de Ciencia Forense

Instituto de Recursos Naturales

Real Casa de la Moneda

Agencia de Pensiones del Profesorado

Agencia de Parques Reales

Laboratorio Famaceútico del Gobierno

Agencia de Servicios de Tecnología de la Información de la S.S.

Agencia de Pasapones del R. Unido

Agencia de Cerificaciones de Vehículos

Agencia de Compensación

Servicio de Prisiones de Irlanda del $N$.

Oficina Meteorológica

Agencia de la S.S. de Irlanda del N.

Agencia de Seguridad y Salud Laboral del Servicio Civil

Propiedades del Sistema Nacional de Salud

Registro de Escocia

Centro de Defensa Animal

Agencia de Ventas

Abogados del Estado

Agencia de Instrucción y Reclutamiento Naval

\section{2}

31

29

28

27

27

27

27

25

25

23

22

21

21

20

19

19

19

19

19

19

19

17

17

17

16

16

16

16

16

16

15

15

15

15

15

15

14

14

14

13

13

13

13

13

13
85

815

505

1.295

250

585

395

605

1.300

1.790

540

540

635

200

45

665

225

625

4.530

450

3.505

600

390

670

130

260

665

380

970

390

260

265

3.535

1.465

75

145

3.590

2.195

4.990

100

105

1.075

220

65

120

5.375
Frecuente

Frecuente

1

(6) 0

2

2

Frecuente

0

(6) 0

2

Frecuente

(6) 0

1

2

Frecuente

0

-

$-$

0

1

(0) 0

0

1

0

0

0

-

(0) 0

0

1

0

0

5

$-$

0

0

$-$

$-$

$-$

Regular 


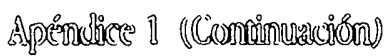

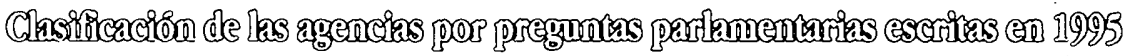

Nombre de la agencia (1)

N. .9 de preguntas
parlamentarias
escritas

Agencia de Recaudación de Tasas

Inspección de Amamento y Material

Parque Wilton

Agencia Escocesil de Ciencia Agraria

Agencia de Aparatos Médicos

Agencia de Compras

Ejecutivo de Servicios de Seguridad

Agencia Fscocesa de Protección de Pesq.

Agencia de Restablecimiento de la S.S.

Escuela del Servicio de Incendios

Inspección de Armamento y Material de I.N.

Servicio de Correas

Agencia de Defensa de la Infancia de l.N.

Agencia de Pensiones de Escocia

Oficina Hidrogrífica

Armamento y Material Militar

Campo de Mantenimiento del Mando de la RAF

Agencia de Pruebas de Vehículos y Conductores

Escuela Militir del Duque de York

Organización de Reparaciones Aeronaúticas

Escuela Reina Victoria

Agencia de Defensa Textil

Agencia de Defensa de los Grupos de Instrucción de la RAF

Agencia de valorición de terrenos

Agencin del Servicio de Informes

Licencias de conducción de $\mathrm{I}$. del $\mathrm{N}$.

Escuela de Servicios a los Niños (Noroeste de Europa)

Agencia de Servicios Analíticos de la Defensa

Agencia de sistemas de Información logística

Oficina de Registro de Escocia

Agencia para Escocia de estudiantes premiados

Agencia de Laboratorios Veterinarios

Agencia de Iniestigación de la $D$.

Senvicio de Salud Laboral del S.C.

Fundación de Ingeniería de Señales de la RAF

Servicio de Tribunales Escoceses

Centro de Conferencias QEII

Agencia de Apoyo de Técnicas del Ejército

Ihitiad de Tecnologia \& Investigación Industrial

Agencia de Distribución \& Almacenaje de las bases del Ejércilo

Ejecutivo de circulación \& transporte de Defensa

\section{2}

11

11

11

11

10

10

9
Personal 1/11/95 (2)

N.. de reuniones entre el Jefe Ejecutivo y el Secretario de Estado

260

1.990

30

140

160

115

1.115

240

90

260

195

455

750

160

795

1.040

8.945

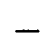

0 


\section{Apéndice 1 (Continuación)}

s

Clasificación de las agencias por preguntas parlamentarias escritas en 1995

\begin{tabular}{|lcr|}
\hline \multicolumn{1}{|c}{ Nombre de la agencia (1) } & $\begin{array}{c}\text { N.o de preguntas } \\
\text { parlamentarias } \\
\text { escritas }\end{array}$ & $\begin{array}{c}\text { N.. de reuniones } \\
\text { entre el Jefe Ejecutivo } \\
\text { el Secretario de Estado }\end{array}$ \\
\hline Agencia de Ciencia Forense de I. del N. & 1 & 0 \\
Agencia del Estado de los Servicios Sociales & 1 & 120 \\
Oficina del Registro Público de I. del N. & 1 & 125 \\
Centro de Análisis de Operaciones de la Defensa & 0 & 95 \\
\hline
\end{tabular}

Fuente: Col. 1: Autores, datos del CD-ROM de la base de datos Justis del Parlamento (POLS); Col. 2: Next Steps Briefing Notes (edición de 1995); Col. 3: entre el 25 de octubre y el 27 de noviem. bre, Gordon Prentice (laborista) hizo una serie de preguntas parlamentarias escritas a los Ministerios pidiendo detalles de la frecuencia de los encuentros entre los Secretarios de Estado y los Jefes Ejecutivos de las Agencias. El nümero de ministerios que se negaron a contestar los detalles de las WPQ, declararon sólo que los encuentros tenian lugar frecuentemente o como y donde. 0 donde surgían los asuntos en concreto. A proposito de las comparaciones de los cruces de deparamentos las respuestas son insuficientes y por lo tanto excluidas de esta tabla.

Notas. 1.- Excluidas de la tabla: la Imprenta del Gobiemo y la Oficina Central Estadistíca, debido a que hay frecuentemente referencias a las contestaciones sustantivas de otras agencias.

2.- Cifras de empleados civiles en abril de 1995. Excluidos los eventuales. Cifras redondeadas en cinco. Las cifras de personal incluyen personal militar de las Agencias del Ministerio de Defensa.

3.- Las agencias en cursiva funcionaban sólo en los papeles en 1995.

4.- Incluye las Fuerzas de Defensa Quimicas y Biológicas y el Centro de Análisis Operacional de la Defensa.

5. Se eliminan 1.284 localidades que ocupan personal.

6. Respuestas referidas sólo al periodo comprendido hasta julio de 1995.

7.- Entrevistas ordinarias con el personal nuevo. 


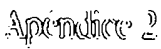

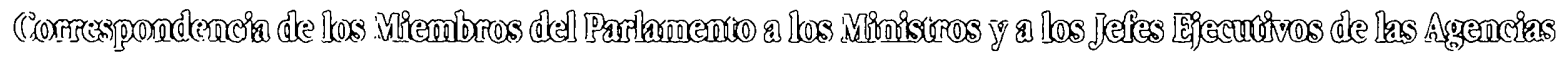

Agencias *

Agencia de Apoyo T'écnico al Ejército

Agencia de diseño asisticlo por ordenador del oeste

\section{$-$}

46

Agencia de Guardacostas

Calsis de Reposo

Agencia de Compensación

Servicio de Justicia

Agencia de Servicios Análiticos de la Defensa

Agencia de Investigación y Evaluación de la Defensa

Servicio de Correos

Agencia de Ventas

Agencia de autorización de conductores y vehículos

Agencia de Pernisos de Conducir

Fiscuela Real Militar Duque de York

Servicio de Empleo

Agencia de Calreteras

Agencia de Relaciones Re:les Históricas

Historico de Escocia

Registro Cattastral de Su Majestad

Servicio de Prisiones de Su Majestad

Servicio de Insolventes

Agencia de Seguridad de la Marina

Oficina Meteorológica

Agencin de instrucción y reclutamiento Naval

Agencia de Pensiones del Servicio Nacional cle Salud

Agencia de Protección a la Infancia de Irlanda del Norte

Servicio de Prisiones de Irlanda del Norte

Agencia de la Seguriclad Social de l. del Norte

Oficina de Estadísticas Nacionales

Oficina de Patentes

Agencia de Retribuciones y Personal

Inspección de Planificación

Scrvicio de Planificación

Oficina de Registro Público

Oficina de Monopolio Público

Agencia de Radiocomunicaciones

Agencia de Recaudación de Tasas

Servicio de Carreteras

Agencia de Parques Reales

Agencia de Pensiones. Oficina de Escocia

Servicio de Prisiones de Escocia

Agencia de Subsidios de la Seguridad Social
N. ${ }^{2}$ de cartas recibidas

1995

1996

\begin{tabular}{cc}
\multicolumn{2}{c}{ N. ${ }^{\circ}$ de cartas recibidas } \\
\hline 1995 & 1996 \\
\hline
\end{tabular}




\begin{tabular}{|c|c|c|}
\hline \multicolumn{3}{|c|}{ Apéndice 2 (Continuación). } \\
\hline \multirow{2}{*}{ Afencias * } & \multicolumn{2}{|c|}{ N..$^{2}$ de cartas recibidas } \\
\hline & 1995 & 1996 \\
\hline Agencia de Protección a la Infancia de la Seguridad Social & 5.554 & 9.110 \\
\hline Agencia de Cotizaciones a la Seguridad Social & 304 & (3) 395 \\
\hline Agencia de Estudiantes Premiados de Escocia & 61 & 120 \\
\hline Agencia de Pensiones del Profesorado (4) & 95 & 59 \\
\hline Agencia de Pasaportes del Reino Unido & 101 & 245 \\
\hline Oficina de Tasación & 221 & 256 \\
\hline Inspección de Vehículos & 42 & 37 \\
\hline Agencia de Pensiones de Guerra & 1.117 & 1.283 \\
\hline Servicio de Aguas & - & 52 \\
\hline
\end{tabular}

Fuentes: HC Debates, del 17 de junio de 1997, volumen 296, cols. 107-10.

Notas: - Las agencias coǹ cartas no registradas no son identificadas sus respuestas en el Parlamento.

1.- Número de empleados civiles en abril de 1995. Excluidos los eventuales. Cifras redondeadas en cinco. Las cifras incluyen el personal militar de las agencias del Ministeno de Defensa.

2.- La Agencia de Subsidios respondí́ a 18.556 cartas de los parlamentanos, enviandolas directamente a las oficinas locales.

3.- Incluye cartas de los parlamentarios a los Ministros en las cuales el jefe ejecutivo contesta en nombre del Ministro.

4.- La Agencia de Pensiones del Profesorado entró a formar parte del Grupo Capita a partir del 1 de octubre de 1996.

Las siguientes agencias reciben entre 1 y 10 cartas de los parlamentarios durante 1996 pero no están en la tabla:

ADAS, Amy Base Repair Organisation, Army Base Storage \& Distrnbution Agency, Ammy Personnel Centre, Cenural Oficce of Information, Central Science Laboratory, Construction Service, Defence Bills Agency, Defence Clothing and Textiles Agency, Defence Secondary Care Agency, Defence Transport ands Movements Executive, Driver and Vehicle Testing Agency, Environment and Heritage Service, Govemement Property Lawyers, Information Technology Services Agency, Land Registers of Northem Ireland, Meat Hygiene Service, Medical Devices Agency, Medicines Control Agency, Military Survey, MOD Police, National Weights and Measures Laboratory, Naval Bases and Supply Agency, Naval Manning Agency, Northem Ireland DVLA, Property Advisers to the Civil Estate, RAF Maintenance Group Defence Agency, Rivers Agency, Scottish Cour Service, Scottish Fisheries Protection Agency, Service Children's Education, The Buying Agency, Training and Employment Agency, Treasury Solicitors Department, Valuation and Lands Agency, Veterinary Laboratories Agency. 
Trnducción de Carmen PIn:iDA Ni:Bor.

- Deparment of Government. University of Strathclyde, Glasgow

- Documento presentado en la reunión anual de la American Political Science, BosIon 3-6 de septiembre de 1998. Está basado en la investigación del proyecto ba audi-
Ioria de la responsabilidad: las agencias y sus múltiples constituciones, financiado por el ESCR como pane de su programa Whintehall. Agradece el autor a Murray McVivar su ajuda en la investigación.

\section{Bibliografia}

Cabinet Office (1996) Next Steps Briefing October 1996. Londres: Oficina del Gabinete.

Cin 2748 (1995) The Civil Senvice: Taking Fonuard Continuity and Change. Londres: HMSO (Imprenta del Gobiemo).

Cliild Support Agency (1994) Annual Report 1993/4 and Business Plan 1994/5. Londres: HMISO.

DıY, P. y R. KI.lin (1987) Accountabilities: Five Public Senices. Londres: Tavistock.

Dowisinc, K. (1995) The Ciril Senice. Londres: Roulledge.

Efficiency Unil (1988) Improwing Management in Govemment: The Next Steps. Londres: HMSO.

HC 313 (1996) Ministerial Accomntability and Responsibility, Comité del Servicio Público, Segundo Informe, Sesión 1995-96. Londres: HMSO

HC 599 (1998) Committee of Public Accounts, The Sale of the Stationery Office, Sesión 1997-98. Londres: Imprenta Nacional.

Hocivoon, B.W., D. Junxi: y M. MCVICAR (1998) .Too much of a good thing?: the pathology of accountability. Paper presentado a la Political Studies Association Anual Conference, Universidad de Keele, 7-9 de abril de 1998.
JUDCII:, D., B. W. Hociw'OOD y M. MCVICAR (1997) The pondlife of executive agencies: Parliament and informatory. accountability, Public Policy and Administration, 12 (2), 95-115.

Learmont Report (Sir John Leamont) (1995) Revietu of Prison Senvice Security in England and Wales and the Escape from Parkburst Prison on 3rd January 1995, Cm 3020. Londres: HMSO.

Misst:Y, A. (1995) After Next Steps. Londres: Oficina del Servicio Público y de la Ciencia.

Next Steps Revien (1996) Next Steps Agencies in Government Rervietu 1995, Cm 3164. Londres:HMSO

Scott Report (Sir Richard Scoll) (1996) Report of the Inquiry into the Export of Defence Equipment and Dual-Use Goods 10 Iraq and Related Prosectutions, Sesión 1995-96, HC 115 (5 volúmenes e indices). Londres:HMSO.

Treasury and Civil Service Committe (1994) The Role of the Ciril Senvice, Informe Quinto, Sesión 1993.94, HC 27 (3 volúmenes). Londres: HMSO. 


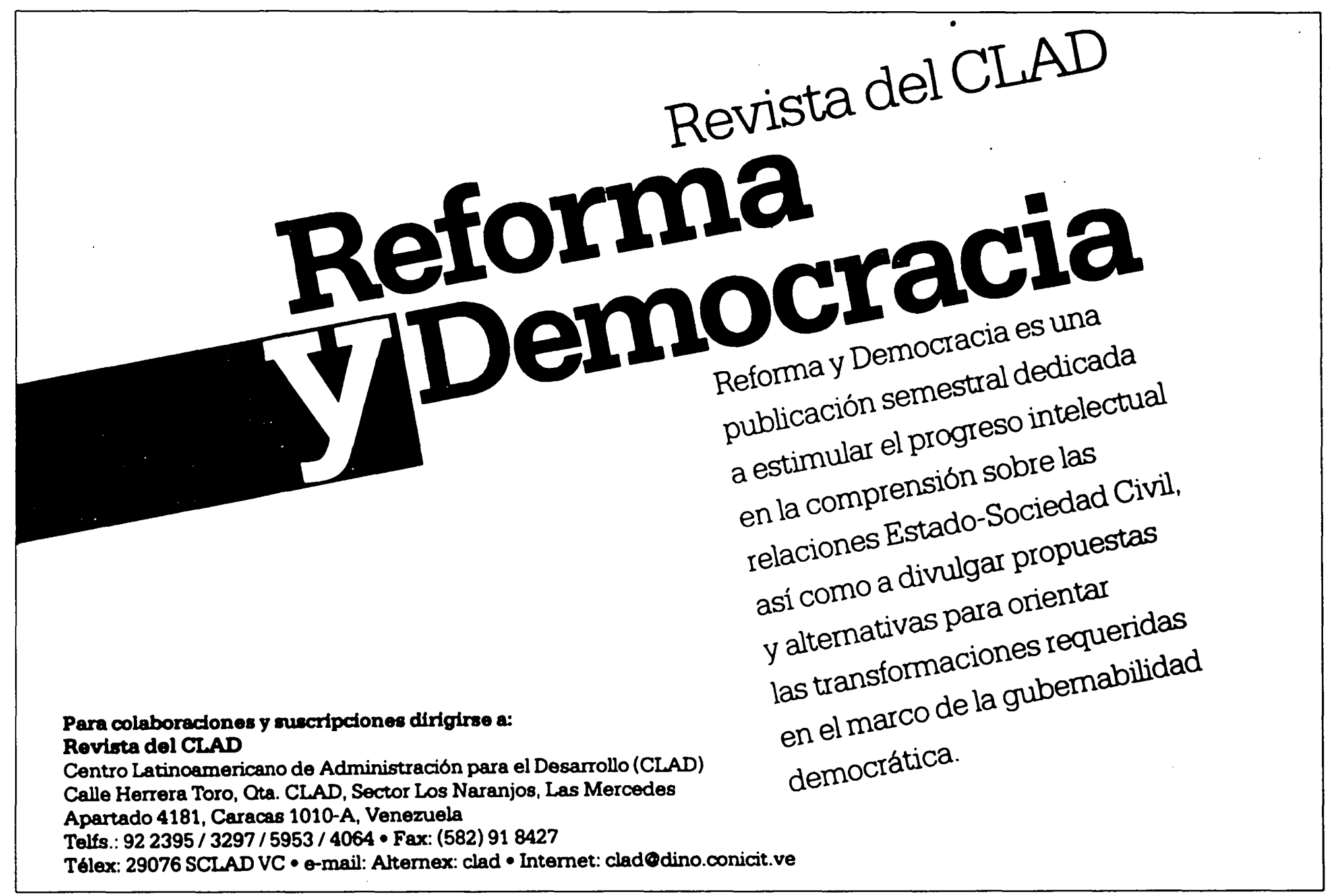

